\title{
TEMÁTICA: Aprendizagem Colaborativa apoiada Por Computador
}

\section{A HIPER-HISTÓRIA NO DESENVOLVIMENTO PSICOMOTOR E NO PROCESSO DE ALFABETIZAÇÃO}

\author{
Luciene Reginato De Lima* \\ Paulo Roberto Bortoli ${ }^{* *}$
}

\section{DADOS DE IDENTIFICAÇÃO}

Instituição: Escola Municipal de Ensino Fundamental de Porto Alegre

Cidade: Porto Alegre - RS

Público Alvo: Alunos do $1^{\circ}$ ciclo

Período de Desenvolvimento do Projeto: 2002 e 2003

\section{RESUMO}

Este trabalho apresenta uma das possibilidades do uso da informática, sendo o próprio aluno o protagonista, como fator de estímulo participativo na construção do conhecimento. Desenvolvido a partir de uma atividade realizada no ano de 2002, com alunos de uma turma de jardim de uma escola de periferia e nível sócio-econômico baixo, com idade variando entre 5 anos e 6 anos e meio, sendo complementado pelos mesmos alunos em 2003, com idade variando entre 6 anos e meio e 7 anos e meio. Tal atividade consistiu, num primeiro momento - 2002 - , da criação e narração de uma história pelos alunos, seguida da escrita textual pela professora da turma. Posteriormente a história foi teatralizada - esta foi filmada - e representada graficamente (desenhos) pelos alunos. Na segunda etapa - 2003 - com os elementos de diferentes mídias e um software de edição de hipermídia foi desenvolvido um programa, utilizando recursos de multimídia e hipertexto, possibilitando a exploração virtual da história pelos protagonistas, a partir desta vivência os alunos, na turma do primeiro ano do primeiro ciclo, criaram alternativas com diferentes desenlaces. Com estas diferentes finalizações foram construídas diferentes continuações da história, tornando-se uma hiper-história, numa vivência recursiva. Pretende-se dar continuidade ao trabalho em mais duas etapas (2004/2005), incluindo-se os desenlaces alternativos criados, cujos textos serão corrigidos pelos alunos, e a teatralização e de cada um deles pelos próprios alunos. Com estes novos materiais será construída uma nova versão da hiper-história.

\footnotetext{
${ }^{*}$ Piscopedagoga - Professora de Séries Iniciais

** Mestre em Educação - Especialista em Informática na Educação - Especialista em Ciências do Esporte. email: prbortoli_educ@terra.com.br
} 


\section{CRONOGRAMA}

\begin{tabular}{|c|c|c|c|c|}
\hline \multirow[b]{2}{*}{ ANO } & \multicolumn{2}{|c|}{ ATIVIDADES } & \multirow{2}{*}{ SITUAÇÃO } & \multirow{2}{*}{$\begin{array}{l}\text { SÉRIE } \\
\text { CICLO } \\
\text { IDADE }\end{array}$} \\
\hline & NA AULA & CICLO DE VIDA & & \\
\hline 2002 & $\begin{array}{l}\text { - } \quad \text { Criação da história } \\
\text { - } \quad \text { Leitura da história } \\
\text { pela professora } \\
\text { - } \\
\text { Teatralização }\end{array}$ & $\begin{array}{l}\text { - Concepção } \\
\text { Pesquisa, estudo, decisão sobre } \\
\text { os aspectos relevantes a para } \\
\text { constituição da } \\
\text { hipermídia/hipertexto com } \\
\text { qualidade e adequada aos } \\
\text { objetivos } \\
\text { - Realização } \\
\text { Filmagem } \\
\text { Digitalização } \\
\text { Edição }\end{array}$ & Concluído & $\begin{array}{ll}\text { - } \quad \text { Jardim } \\
\text { - } 1^{\circ} \text { ano do } 1^{\circ} \\
\text { ciclo } \\
\text { - } \quad 5 \text { anos a } 6 \\
\text { anos e meio }\end{array}$ \\
\hline 2003 & $\begin{array}{ll}\text { - } & \text { Revisitação } \\
\text { - } & \text { havegação no } \\
\text { hipertexto } & \text { Construção da } \\
\text { continuação da } \\
\text { história (texto e } \\
\text { desenho) }\end{array}$ & $\begin{array}{l}\text { - Realização } \\
\text { Desenvolvimento de } \\
\text { hipermídia/hipertexto, utilizando } \\
\text { recursos, técnicas e meios } \\
\text { apropriados, definidos na fase } \\
\text { anterior (concepção) sobre o tipo } \\
\text { de produto desejado } \\
\text { - Validação } \\
\text { Testagem da aplicação: } \\
\text { funcionalidade, adequação aos } \\
\text { objetivos estabelecidos e a } \\
\text { correspondência ao produto } \\
\text { desejado, em relação aos aspectos } \\
\text { didáticos, técnicos, funcionais, } \\
\text { estéticos, etc. ... } \\
\text { - Difusão/Exploração } \\
\text { Exploração pelos usuários finais, } \\
\text { numa determinada situação de } \\
\text { ensino e de aprendizagem }\end{array}$ & Concluído & $\begin{array}{ll}\text { - } & 1^{\mathrm{a}} \text { série } \\
\text { - } & 2^{\mathrm{o}} \text { ano do } 1^{\circ} \\
& \text { ciclo } \\
\text { - } & 6 \text { anos a } 7 \\
& \text { anos e meio }\end{array}$ \\
\hline 2004 & $\begin{array}{l}\text { Discussão e } \\
\text { correção dos textos } \\
\text { da continuação da } \\
\text { história, pelos } \\
\text { alunos }\end{array}$ & $\begin{array}{ll}\text { - } & \text { Concepção } \\
\text { - } & \text { Realização }\end{array}$ & Previsto & $\begin{array}{ll}\text { - } \quad 2^{\mathrm{a}} \text { série } \\
\text { - } \quad 3^{\mathrm{o}} \text { ano do } 1^{\mathrm{o}} \\
\text { ciclo } \\
\text { - } 7 \text { anos a } 8 \\
\text { anos e meio }\end{array}$ \\
\hline 2005 & $\begin{array}{ll}\text { - } & \text { Nova revisitação } \\
\text { Representação da } \\
\text { História com seus } \\
\text { diferentes } \\
\text { desenlaces }\end{array}$ & $\begin{array}{ll}\text { - } & \text { Realização } \\
\text { - } & \text { Validação } \\
\text { - } & \text { Difusão/Exploração }\end{array}$ & Previsto & $\begin{array}{ll}\text { - } & 3^{\mathrm{a}} \text { série } \\
\text { - } & 1^{\mathrm{o}} \text { ano do } 2^{\circ} \\
& \text { ciclo } \\
\text { - } & 8 \text { anos a } 9 \\
& \text { anos e meio }\end{array}$ \\
\hline
\end{tabular}

Obs,:

- A última coluna apresenta a série no ensino regular e sua correspondência no ensino ciclado, além da idade aproximada dos alunos.

- $\quad$ Na fase de Difusão e Exploração (Revisitação) os alunos utilizaram o programa em grupos de três.

- O trabalho foi financiado pelos próprios autores.

- O software (editor de hipermídia, editor gráfico, editor de texto, editor de vídeo, etc.), o hardware (computadores, impressora, gravador de CD, placa digitalizadora de vídeo, scanner, câmera digital, cartão de memória, filmadora, etc. ), o material de consumo (papel, CD-R, CD, RW, tinta para impressora, fitas para filmadora, baterias, etc.) utilizados na construção do aplicativo (Realização) e necessários para a pesquisa pertencem aos autores.

- O microcomputador (multimídia, com SO Windows) utilizado na fase de Difusão e Exploração pelos alunos foi cedido pelo SSE da Escola. Não foi possível utilizar o Laboratório de Informática da Escola pelo fato de que o sistema operacional instalado (LINUX) não executa aplicativos .EXE, desenvolvidos para o ambiente Windows. 


\section{JUSTIFICATIVA}

Entendemos que as experiências vividas através da interação do corpo infantil com os objetos do conhecimento signifiquem muito mais para o aprendente quando as mesmas utilizam-se da imaginação e ação. Segundo Rosa (2002) brincando a criança imita naturalmente o cotidiano da vida, nas brincadeiras expontâneas "ela descobre os ajustes diversos, complexos e progressivos da atividade motriz", sendo os movimentos gerados importantes para a "interação das diversas funções neurológicas, motrizes e psíquicas"

Observamos também que as crianças que já têm acesso ao mundo informatizado podem, além de divertir-se e desenvolver-se, na interação com os equipamentos, participar da criação de novas possibilidades de escrita e leitura.

\section{INTRODUÇÃO}

O presente trabalho tem por objetivo demonstrar uma possibilidade de utilização de hipermídia e hiper-história associadas à vivência lúdica e criativa de crianças em pleno processo de alfabetização escolar em uma escola pública de Porto Alegre.

Visa ampliar as possibilidades metodológicas de ensino, proporcionando ao professor mais uma ferramenta de trabalho que coloca o aluno como participante de sua aprendizagem.

Une o fazer pedagógico de uma professora de Educação Infantil e do Ensino Fundamental e um professor também do Ensino Fundamental e criador de alternativas pedagógicas na área de Informática, tanto para alunos plenos de suas capacidades como para alunos com necessidades especiais de aprendizagem.

\section{OBJETIVOS}

$>$ Possibilitar ao aluno a utilização do computador para interagir com suas próprias idéias, vivências e o mundo letrado.

$>$ Estimular a imaginação na criação de histórias e representá-las com o próprio corpo.

$>$ Proporcionar a leitura e escrita de histórias, tendo o aluno como autor e protagonista.

$>$ Ampliar o vocabulário.

\section{METODOLOGIA}

O trabalho com a turma A12 desenvolveu-se em pequenos projetos que buscavam compreender determinados objetos do conhecimento pertencentes ao mundo que os rodeava.

Naquele momento, o grupo também estava estudando uma série de informações e construindo conceitos sobre aviões e, posteriormente, iríamos realizar uma visita ao Aeroporto de Porto Alegre para verificar algumas hipóteses e ampliar conhecimentos. Portanto, a motivação para um passeio estava muito presente.

Dentre as várias estratégias previstas para a execução do projeto de ensino estavam sendo desenvolvidas também estratégias que possibilitariam o desenvolvimento 
de outras áreas do conhecimento, tais como: a leitura, a imaginação, a criação de histórias.

Foi, então, nesse ambiente motivador, que a História da Turma A12 foi construída. A professora iniciou a atividade com os alunos sentados em círculo, cada um acrescentando mais um elemento à história, na sua vez de falar.

O texto foi sendo escrito numa folha, pela professora, e lido para os alunos, que mantiveram-no como foi construído.

O texto final está a seguir:

\author{
UMA VEZ A TURMA A12 FOI \\ PASSEAR DE ÔNIBUS NUM \\ PARQUE QUE FICAVA PERTO DE \\ UM CINEMINHA.
QUANDO ESTAVAM LÁ, ELES
VIRAM UMA BARRACA E UMA
RODA-GIGANTE. \\ OS ALUNOS FORAM ENTRAR NA \\ BARRACA PARA OLHAR E \\ DESCOBRIRAM QUE HAVIA \\ BRINQUEDOS. APARECEU UM \\ MONSTRO DE BRINQUEDO QUE \\ RODEAVA O CORPO, A CABEÇA \\ BALANÇAVA E AINDA ABRIA A \\ BOCA. \\ DE REPENTE, APARECEU UM \\ PALHAÇO DE DENTRO DE UM \\ BALÃO MÁGICO E VEIO UM LOBO \\ DE DENTRO DA FLORESTA E \\ COMEU TODO MUNDO.
}

O IGOR SE SALVOU E ESPETOU

BUNDA DO LOBO MAU.

ANDREY, QUE TAMBÉM HAVIA

ESCAPADO, SE JUNTOU COM O

IGOR PARA AJUDAR A SALVAR OS

COLEGAS, ACHANDO UMA

FAQUINHA PARA MATAR O LOBO.

ABRIRAM ELE PELA BARRIGA E

RETIRARAM TODOS DALI DE

DENTRO, MANDANDO O LOBO PARA

UM HOSPITAL SE CUIDAR E PARA 


\section{UMA ESCOLA APRENDER A RESPEITAR OS OUTROS.}

\section{AUTORES: ALUNOS DA TURMA A12 \\ E PROF ${ }^{a}$. LUCIENE}

Num outro dia, a história foi colocada em uma folha, no quadro e a professora leu o texto em voz alta para os alunos, apontando com o dedo embaixo das palavras. Solicitou aos alunos que procurassem algumas palavras significativas no texto, circulando-as na medida em que iam sendo localizadas. Juntamente a esse exercício com os aprendizes-construtores, era solicitada a análise das palavras, identificando a primeira letra e demais letras das mesmas.

Dias depois, numa conversa informal com o professor co-autor do presente projeto, foi discutida a possibilidade de transformar o texto construído num hipertexto para ser manuseado no computador.

A proposta foi discutida, planejada e alguns dias depois iniciou o trabalho de teatralização, filmagem e informática, com os materiais selecionados.

Durante o trabalho de filmagem, após um dialogo, os alunos teatralizaram espontaneamente, criando movimentos e gestos representativos da história, sendo sugeridos alguns sinais LIBRAS (Língua Brasileira de Sinais).

Foi também sugerida aos alunos a produção de desenhos para ilustrar a história que iria ao computador. Alguns alunos desenharam, os desenhos foram apreciados pelos mesmos e foi selecionado aquele que representava mais detalhes da história.

Iniciou, então, o desenvolvimento do programa, utilizando-se o sistema de autoria de multimídia SuperLink na construção da aplicação hipermídia/hipertexto, seguindose as fases (concepção, realização, validação, difusão e exploração) do processo de evolução do ciclo de vida de uma aplicação que utiliza recursos multimídia, tomando-se por referência Costa (1998), citado por Bortoli (2000). Com a ferramenta SuperLink e baseando-se no ciclo de vida proposto transformou-se os elementos produzidos e constituintes do trabalho em um programa de hipermídia e hipertexto, possibilitando, posteriormente, aos alunos interagir com a vivência num novo contexto (Figuras 01A/B). A partir da revisitação virtual de sua história os alunos, agora já escrevendo, elaboraram diferentes finais. Estes foram incluídos numa continuação da história, tornando-se, então, uma hiper-história com varias ligações (Figura 02), que também foi explorada por eles, cada link apresenta uma nova página com um texto sobre "o lobo na escola" e um desenho representando graficamente este mesmo texto (ex.: figura 03), num processo recursivo que pretende-se continuar nos próximos anos. Serão mais duas etapas, em 2004 discussão e correção dos textos com as diferentes finalizações pelos próprios alunos, com a mediação da professora e o desenvolvimento de hipermídia/hiper-história utilizando estes textos, em 2005 os aluno farão nova revisitação da história, seguida da teatralização dos diferentes desenlaces, pretende-se incluir estas representações numa nova versão da hiper-história. 
Figura 01 - A
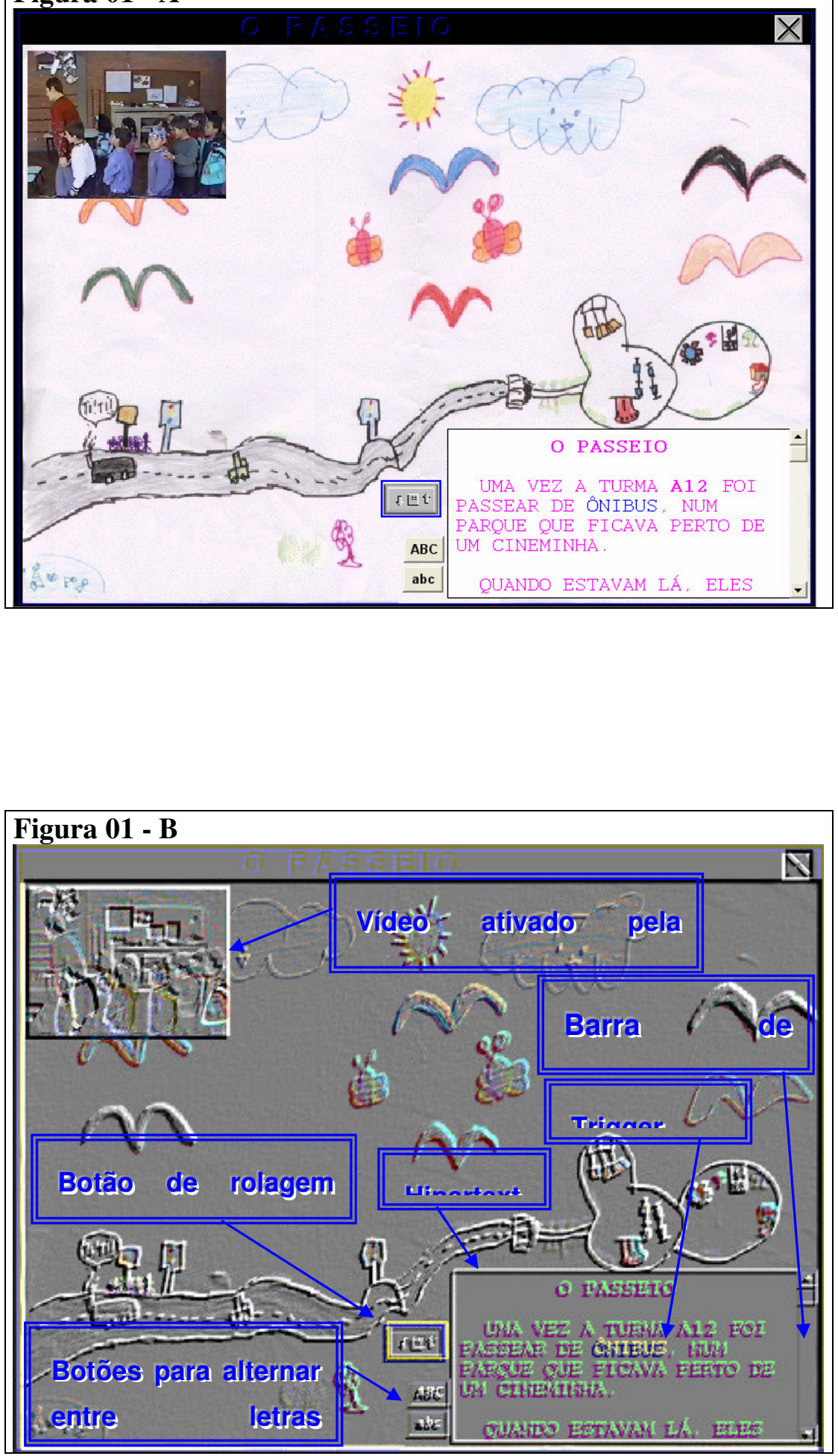


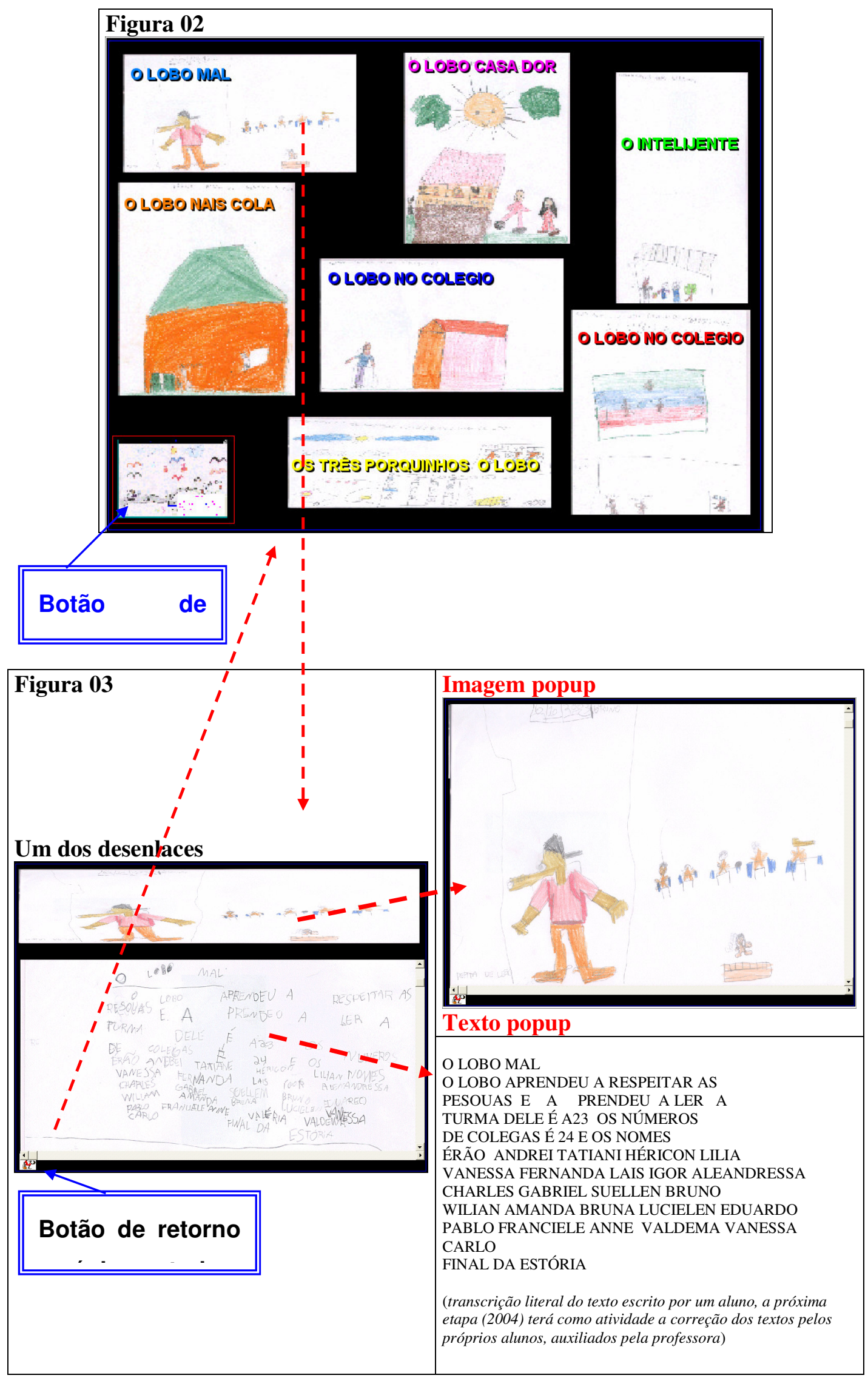




\section{REFERENCIAL TEÓRICO}

A sociedade atual está repleta de portadores de texto pelos mais variados locais por onde circulamos, desde instituições altamente letradas e reconhecidas por esse status até mesmo os ambientes naturais que recebem embalagens povoadas pelas letras.

Existem pessoas nesse contexto que diariamente interagem com os demais se utilizando a linguagem escrita muito mais do que da linguagem oral. No entanto, há grupos que interagem entre si utilizando-se apenas da linguagem oral, sem a menor necessidade de dominar os signos linguiísticos.

Ao trabalharmos com pessoas oriundas desses grupos minoritários, em que a escrita e a leitura não são essenciais e nem se fazem necessárias, nos deparamos com um difícil obstáculo, que é o de tornar alfabetizados alunos que não vêem significado algum na apropriação dos códigos escritos, além de não necessitarem utilizar os mesmos para a sua sobrevivência.

Observa-se, portanto, que muitos textos estão à disposição desses leitores sem que haja a menor interação com os mesmos. Os leitores em potencial necessitam de outros leitores, aptos a introduzi-los no maravilhoso universo da comunicação escrita.

Porém interação do indivíduo com o meio ocorre precocemente e é influenciada por sua ação psicomotora, segundo Le Boulche (1992), o recém-nascido já apresenta a necessidade de expressar-se e comunicar-se, num intercâmbio interpessoal, inicialmente corporal, tornando-se progressivamente corporal e verbal, "mostrando as relações estreitas entre linguagem e motricidade".

Cagliari (1994), afirma-nos que, assim como a criança precisa de mediadores experientes para aprender a falar naturalmente e se inserir no contexto da comunicação, necessitam também de mediadores capazes de motivar-lhe a escrita, transformando-a em mais uma forma de expressão social, artística, como um criativo passatempo, para deixar de tornar-se estranha, indesejável ou inútil no contexto escolar.

Acrescenta que as crianças devem participar com empenho do aprendizado da escrita, gostando de serem escutadas, de darem idéias e de colocarem suas expectativas. Observa que na escrita de textos espontâneos, as crianças se preocupam em expor conceitos pessoais, sua visão de mundo e da vida, de forma objetiva e direta ou através da fantasia parecida com a dos contos de fadas.

Cabe à Escola a tarefa de tornar a escrita um exercício extremamente prazeroso, pois seu objetivo primeiro é permitir a leitura. Pode se tornar uma atividade lúdica sem necessariamente se transformar num exercício enfadonho e sem significado.

Os avanços tecnológicos nos possibilitam também variados recursos capazes de qualificar e significar o trabalho de alfabetização.

Destacamos no presente trabalho, a importante contribuição da Hiper-história, que tem como base o construtivismo como paradigma epistemológico, conceitos multimediais e interação aprendiz-máquina para a construção de estrutura de conhecimento através da navegação e livre exploração .

Segundo Peña, em artigo publicado em 1999, as hiper-histórias assemelham-se a histórias literárias convencionais, porém, numa versão eletrônica, mesclando o lúdico, o uso de imagens e sons, criando a possibilidade de escolher e construir múltiplas alternativas de narrativas a partir de um relato ou alguma idéia preexistente.

Sánchez (2003), acrescenta, ainda, a possibilidade do aprendiz participar da tarefa de aprendizagem, sendo estimulado a comunicar-se e construir novas aprendizagens significativas. 


\section{CONCLUSÃO}

A definição por esta forma de trabalho, que foi construída ao longo de trocas pedagógicas com outros professores, cursos de qualificação e formação, tentativas e erros, reafirma o que nos propõe o psicólogo soviético L. S. Vygotysk, citado por Javier Onrubia (1999), concluindo que é necessário criar desafios partindo do aluno, utilizando diversos meios e instrumentos de apoio, realizando tarefas conjuntas, com a ajuda de outros, para posteriormente atingir a realização das mesmas num nível superior, de forma individual.

É a posição que defende a importância da interação entre as pessoas e o seu conhecimento, dando origem aos processos de aprendizagem e desenvolvimento humanos.

Esta atividade representou para os alunos, em 2002, um ganho muito positivo no aspecto da motricidade quando da teatralização e, nos primeiros passos da alfabetização, ao criarem a História e acompanharem a leitura com a professora. Na revisitação, em 2003, evidenciou-se o aumento da auto-estima, do interesse pela leitura, como, também, pela escrita quando criaram os diferentes desenlaces.

Assim pretendemos que nossos alunos se desenvolvam, apoiados pelas experiências significativas e com modelos que lhes possibilitem aventurar-se pelos códigos de comunicação humana.

\section{REFERÊNCIAS BIBLIOGRÁFICAS}

BORTOLI, Paulo Roberto. Software educacional lúdico: uma ferramenta para auxiliar o surdo no processo de construção de seu vocabulário escrito. - Fac. de Educação, PUCRS. Porto Alegre, 2000. 288 p. Dissertação (Mestrado)

CAGLIARI, Luiz Carlos. Alfabetização \& Lingüística. São Paulo: Ed. Scipione, 1994. KHERIAT, Larry. SuperLink para Windows - Versão 2.0 - Washington Computer Services. Rio de Janeiro. IBM, 1994.

LE BOULCH, Jean. O desenvolvimento psicomotor: do nascimento aos 6 anos. Trad. por Ana Guardiola Brizolara. Porto Alegre, Artes Médicas, 1982. 220p.

ONRUBIA, Javier \& Outros. O construtivismo na sala de aula. São Paulo: Ed. Ática, 1999.

PEÑA, Patrícia. Softwares educativos: Para aprender jugando en mundos digitales.

Artigo publicado no serviço informativo ibero-americano- Febrero 1999. Organizácion de Estados Ibero-americanos. Disponível em:

<http://www.oei.org.co/sii/entrega8/art15.htm >. Acesso em: 20 de jul. 2003.

ROSA NETO, Francisco. Manual de avaliação motora. Porto Alegre: Artmed Editora, 2002.

SÁNCHEZ, Jaime; CERNUZZI, Luca. Hiper-histórias para hiper-aprender.

Universidade do Chile, Santiago. Disponível em : <www.dcc.uchile.cl/ jsanchez/Pages/ papers/hyperhistorias.pdf>. Acesso em: 20 de set. 2003. 


\section{ANEXO}

\section{GALERIA DE FOTOS}

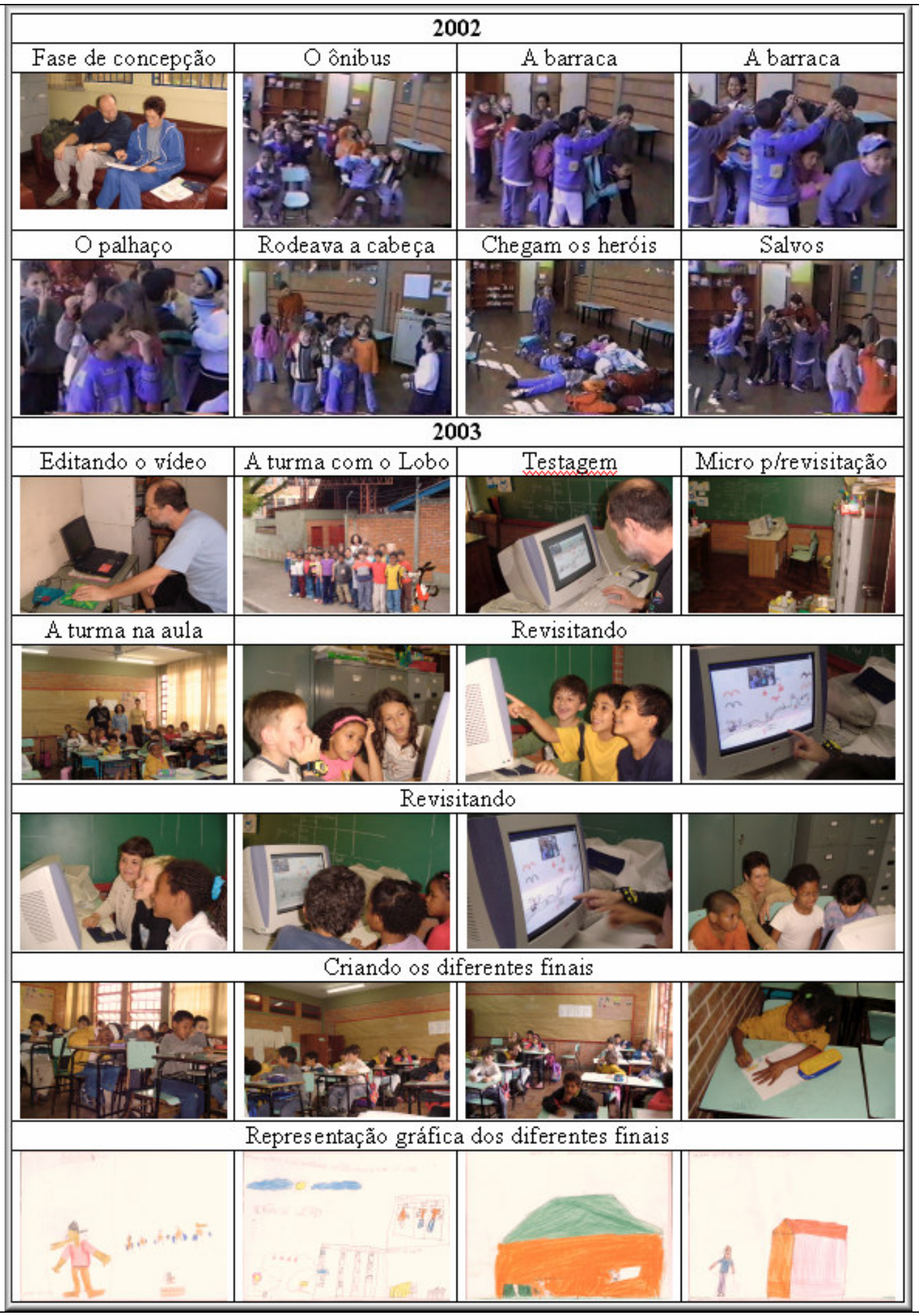

